\title{
Comparative Analysis of Single and Hybrid Neuro- Fuzzy-Based Models for an Industrial Heating Ventilation and Air Conditioning Control System
}

\author{
Sina Ardabili \\ Institute of advanced studies \\ Koszeg \\ University of Pannonia \\ Koszeg, Hungary. \\ 0000-0002-7744-7906
}

\author{
Bertalan Beszedes \\ Alba Regia Technical Faculty \\ Obuda University \\ Budapest, Hungary. \\ beszedes.bertalan@amk.uni- \\ obuda.hu \\ Amir Mosavi 1,2* \\ ${ }^{1}$ Department of Mathematics and \\ Informatics, J. Selye University \\ Komarno, Slovakia. \\ ${ }^{2}$ Bauhaus Universität Weimar \\ Weimar, Germany \\ 0000-0003-4842-0613
}

\author{
Laszlo Nadai \\ Kalman Kando Faculty of \\ Electrical Engineering \\ Obuda University. \\ Budapest, Hungary \\ 0000-0001-8216-759X \\ Felde Imre \\ Kalman Kando Faculty of \\ Electrical Engineering \\ Obuda University \\ Budapest, Hungary \\ 0000-0003-4126-2480
}

\author{
Karoly Szell \\ Alba Regia Technical Faculty \\ Obuda University \\ Budapest, Hungary. \\ 0000-0001-7499-5643
}

\begin{abstract}
Hybridization of machine learning methods with soft computing techniques is an essential approach to improve the performance of the prediction models. Hybrid machine learning models, particularly, have gained popularity in the advancement of the high-performance control systems. Higher accuracy and better performance for prediction models of exergy destruction and energy consumption used in the control circuit of heating, ventilation, and air conditioning (HVAC) systems can be highly economical in the industrial scale to save energy. This research proposes two hybrid models of adaptive neuro-fuzzy inference system-particle swarm optimization (ANFIS-PSO), and adaptive neuro-fuzzy inference system-genetic algorithm (ANFIS-GA) for HVAC. The results are further compared with the single ANFIS model. The ANFIS-PSO model with the RMSE of 0.0065 , MAE of 0.0028 , and $R^{2}$ equal to 0.9999 , with a minimum deviation of $0.0691(\mathrm{KJ} / \mathrm{s})$, outperforms the ANFIS-GA and single ANFIS models.
\end{abstract}

Keywords-Adaptive neuro-fuzzy inference system, ANFISPSO, ANFIS-GA, HVAC, hybrid machine learning

\section{INTRODUCTION}

Machine learning has become essential for the advancement of novel control systems in various applications domains [1-3]. Machine learning methods are fast evolving to deliver more intelligent control systems with the higher performance [4-6]. Machine learning has been reported highly beneficial in the control systems of heating, ventilation, and air conditioning (HVAC) mechanisms [7-9]. Artificial neural networks (ANN), decision trees (DT), adaptive neuro-fuzzy inference system (ANFIS) and multilayer perceptron (MLP) are among the most popular machine learning methods used in HVAC control systems [10-15].

The recently proposed machine learning models for HVAC control systems are reported promising for energy saving and reducing energy deviation [16-20]. Thus, the improvement of machine learning models for higher accuracy and performance is essential [21-23]. However, the research is in the early stage, as the recent literature suggests a great potential in machine learning and many rooms to explore the application of new methods [24-27]. Soft computing techniques and optimization algorithms are shown beneficial in the preprocessing and postprocessing HVAC data [28-31]. However, the application of the hybrid machine learning models has been limited in this realm $[11,24]$. Considering the higher performance reported in using hybrid machine learning models in other control systems, e.g., [32-35], a research gap is apparent in the advancement of HVAC control systems.

The contribution of this paper is to propose two new hybrid machine learning models, i.e., adaptive neuro-fuzzy inference system-particle swarm optimization (ANFIS-PSO), and adaptive neuro-fuzzy inference system-genetic algorithm (ANFIS-GA) to improve the performance of an HVAC control system. The results are to be compared with the previously proposed ANFIS model [15] to evaluate the performance of the hybrid model. Section two represents the description of the dataset and methods, and the results are presented in section three. 


\section{MATERIALS AND METHODS}

\section{A. Experimental data}

The study's experimental data are gathered from an HVAC system used for the temperature-control mushrooms production room with a volume equal to $643.5 \mathrm{~m}^{3}$. Fig. 1 shows a schematic representation of the 5 parts of the system exergy adopted from [15]. Nine sensors, i.e., five platinum resistance thermometers, two board mount humidity detectors, and two manometers, are set to collect the temperature, relative humidity, and pressure data. The DAQMaster and data loggers are also used for sensor data management to configure parameters, real-time monitoring, and store the data. The detailed statement of the energy and exergy analysis of the HVAC system is available in [15].

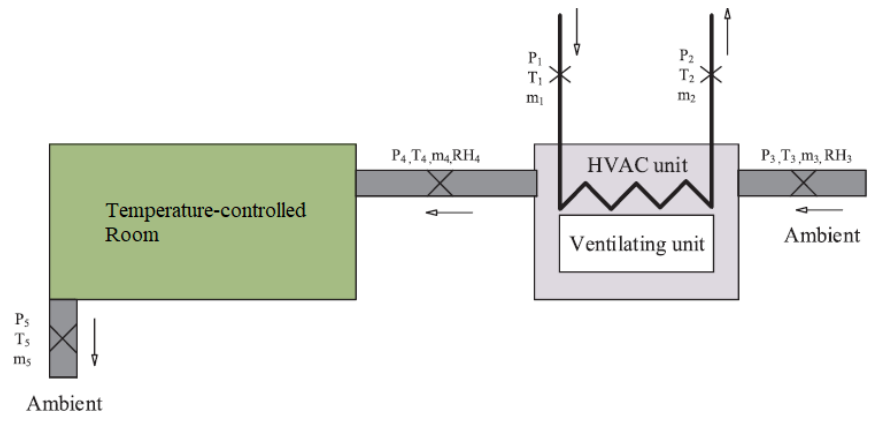

Fig. 1. Schematic representation of the HVAC unit used for the data collection

\section{B. Hybrid machine learning methods}

The two hybrid methods of ANFIS-GA and ANFIS-PSO are used to develop the prediction models of exergy destruction and energy consumption. Both proposed methods have recently been gained popularity for advancing prediction models in a wide range of engineering applications including the control systems [36-39]. The ANFIS-GA hybridizes the components of a single ANFIS and genetic algorithm (GA) [40]. GA efficiently tunes the ANFIS controller through a global optimization represented by a set of ANFIS parameters, i.e., finding the optimum ANFIS parameters, see Fig. 2 [41]. ANFIS-GA has previously shown to outperform the accuracy of a single ANFIS model used in a control system [42]. Thus, it is expected that this hybrid form of ANFIS provides promising results.

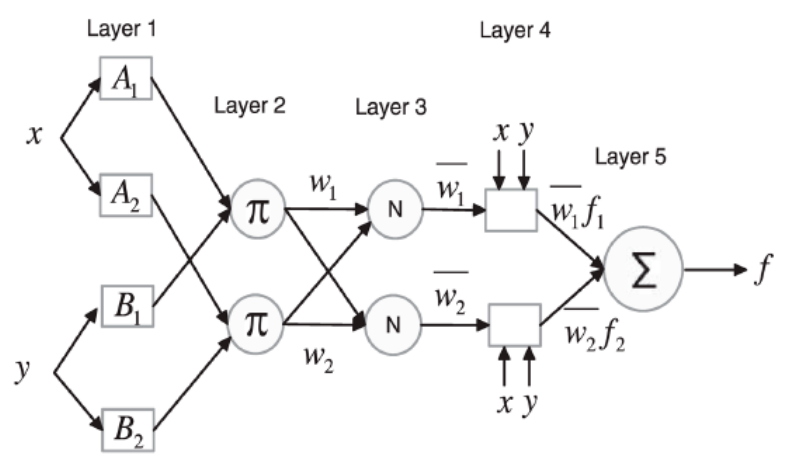

Fig. 2. Schematic representation of the ANFIS layers
In ANFIS, the model variables are constituted by the computation expressions of fuzzy logic and ANNs within the framework of five layers (see Fig.2). According to [43], in the first layer the $n$ nodes are defined based on the Gaussian functions as follows;

$$
O_{i}^{1}=\beta X=\exp ^{\left(-\frac{1}{2} \frac{x-z^{2}}{\sigma^{2}}\right)}
$$

where $\mathrm{O}, \mathrm{Z}$, and $\sigma$, are output, the center of Gaussian function, and variance. The second and third layers ensure the accuracy of qualification and strength normalization of the model as follows;

$$
\begin{aligned}
O_{i}^{2}=W_{i} & =\beta_{A i} X \cdot \beta_{B i}(X) \\
O_{i}^{3} & =\frac{W_{i}}{\sum W_{i}}
\end{aligned}
$$

The fourth layer presents the effect of rules on outputs, where $n_{i}, m_{i}$ and $r_{i}$ represent the ANFIS linear parameters. The model further aims at reducing the difference between predicted values and experimental data as follows;

$$
O_{i}^{4}=\bar{w}_{i} f_{i=} \bar{w}_{i}\left(m_{i} X_{1}+n_{i} X_{2}+r_{i}\right)
$$

In the last layer the weighted average summation is used to deliver a qualitative form of the model as follows;

$$
O_{i}^{5}=Y=\sum_{i} \bar{w}_{i} f_{i=} \bar{w}_{1} f_{1}+\bar{w}_{2} f_{2}=\frac{\sum W_{i} f_{i}}{\sum W_{i}}
$$

Fig. 3 represents a schematic adaptation of the ANFIS-GA from [39], where a detailed description of the model flowchart is given.

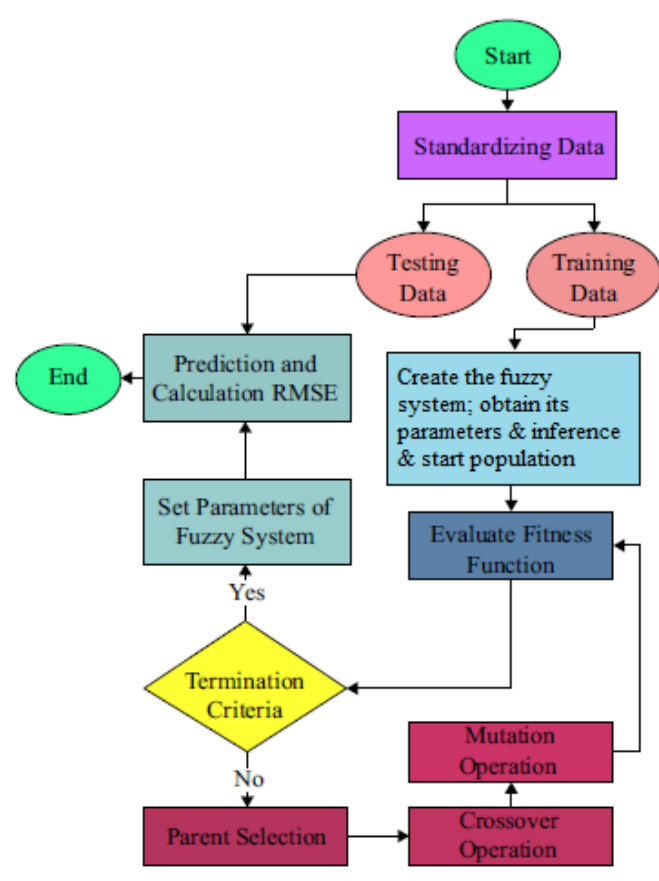

Fig. 3. Schematic representation of ANFIS-GA model

The second model is ANFIS-PSO to calculate the exergy destruction and energy consumption of the HVAC control 
system. ANFIS-PSO has recently shown outstanding results in enhancing the control systems [44]. Therefore, it has been chosen for this case study. ANFIS-PSO has been first proposed for the prediction of the wind power energy [45], where PSO represented a reliable approach for tuning the ANFIS parameters using a low number of variables for proper implementation, as presented in Fig. 4.

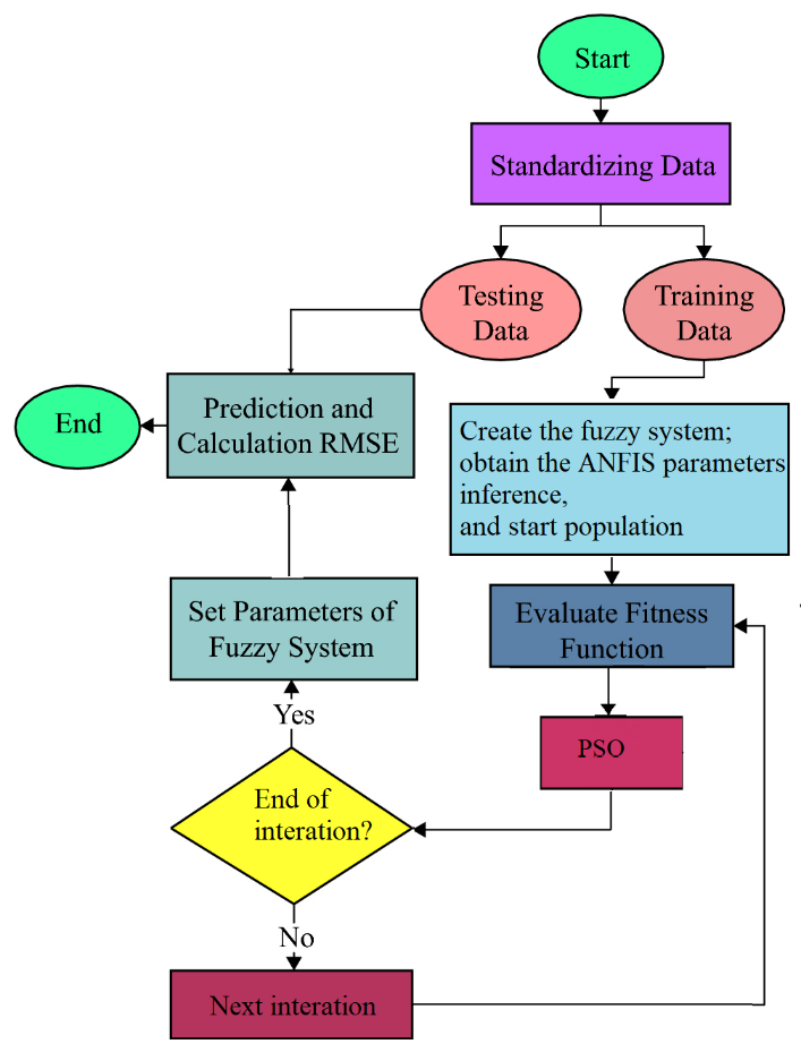

Fig. 4. Schematic representation of ANFIS-PSO model

The swarm in the PSO algorithm works based on random particles, which are the model solutions for tuning the ANFIS. Thus, the performance of each particle is assessed according to its fuzzy system. In ANFIS-PSO, the PSO is used to optimize the parameters of the fuzzy system as follows;

$R_{i}$ : if $x_{1}(k)$ is $A_{i 1}$ and $\ldots x_{n}(k)$ is $A_{i n}$, then $u(k)$ is $a_{i}$

where $x_{n}(k), u(k)$, and $k$ represent the input variables, output variables, and time. And the $\vec{S}_{l}, \vec{V}_{l}$, and $\vec{P}_{l}$ represent the position, velocity, and vector of particles, respectively, where:

$$
\overrightarrow{S_{l}}(t+1)=\overrightarrow{S_{l}}(t)+\vec{V}_{l}(t+1)
$$

The optimum global value in the solution space of $P_{S}$ is $\overrightarrow{P_{l}^{g}}$ [46]. The PSO identifies the optimal antecedent parameters after the rule generation and initialization. The error-index $E(t)$ represents the evaluation function.

\section{Evaluation metrics}

The evaluation metrics of root mean square error (RMSE), Pearson correlation coefficient (R), and mean absolute error (MAE) are used to evaluate the performance of the models as follows;

$$
\begin{gathered}
R M S E=\sqrt{\frac{1}{N} \sum_{i=1}^{N}(A-P)^{2}} \\
R=\left(1-\left(\frac{\sum_{i=1}^{n}(A-P)^{2}}{\sum_{i=1}^{n} A_{i}^{2}}\right)\right)^{1 / 2} \\
M A E=\frac{\sum_{i=1}^{n}|A-P|}{N}
\end{gathered}
$$

In both stages of training and testing, the RMSE, $\mathrm{R}^{2}$, and MAE values are calculated.

\section{RESULTS}

The models are built based on the total exergy destruction of the system, i.e., output variable. The ambient temperature, air flow rate, and water flow rate ambient relative humidity are considered as independent variables, i.e., network inputs. The $70 \%$ of the data are used for training and $30 \%$ for testing. Table. I represents the training results for the three models. ANFISPSO shows better results compared to ANFIS and ANFIS-GA.

TABLE I. TRAINING RESULTS

\begin{tabular}{|c|c|c|c|c|}
\hline Method & Structure & RMSE & MAE & $\begin{array}{c}\text { Deviation } \\
(\text { KJ/s })\end{array}$ \\
\hline ANFIS & $\begin{array}{c}\text { MF type: Gaussian } \\
\text { Number of MFs: } 3 \\
\text { Output: linear } \\
\text { Optimizer type: hybrid }\end{array}$ & 0.024 & 0.014 & 0.3547 \\
\hline $\begin{array}{c}\text { ANFIS- } \\
\text { GA }\end{array}$ & $\begin{array}{c}\text { Max generation=282 } \\
\text { Population size }=200\end{array}$ & 0.005 & 0.0038 & 0.2123 \\
\hline $\begin{array}{c}\text { ANFIS- } \\
\text { PSO }\end{array}$ & $\begin{array}{c}\text { Max iteration=204 } \\
\text { Swarm size }=250\end{array}$ & $\mathbf{0 . 0 0 1 7}$ & $\mathbf{0 . 0 0 0 9 1}$ & $\mathbf{0 . 0 5 0 2}$ \\
\hline
\end{tabular}

Table. II represents the testing results for the three models. ANFIS-PSO shows better results compared to ANFIS and ANFIS-GA. Furthermore, Fig. 5 presents predicted values with $\mathrm{R}^{2}$ for all the models. The comparative analysis of the deviation from the target value for the exergy destruction for all the models is given in Fig. 6 where ANFIS-PSO has delivered the minimum deviation.

TABLE II. TESTING RESUlts

\begin{tabular}{|c|c|c|c|c|}
\hline Method & Structure & RMSE & MAE & $\begin{array}{c}\text { Deviation } \\
(\mathrm{KJ} / \mathrm{s})\end{array}$ \\
\hline ANFIS & $\begin{array}{c}\text { MF type: Gaussian } \\
\text { Number of MFs: } 3 \\
\text { Output: linear } \\
\text { Optimizer type: hybrid }\end{array}$ & 0.068 & 0.04 & 0.9694 \\
\hline $\begin{array}{c}\text { ANFIS- } \\
\text { GA }\end{array}$ & $\begin{array}{c}\text { Max generation=282 } \\
\text { Population size=200 }\end{array}$ & 0.0396 & 0.0226 & 0.5443 \\
\hline $\begin{array}{c}\text { NFIS- } \\
\text { PSO }\end{array}$ & $\begin{array}{c}\text { Max iteration=204 } \\
\text { Swarm size=250 }\end{array}$ & $\mathbf{0 . 0 0 6 5}$ & $\mathbf{0 . 0 0 2 8}$ & $\mathbf{0 . 0 6 9 1}$ \\
\hline
\end{tabular}



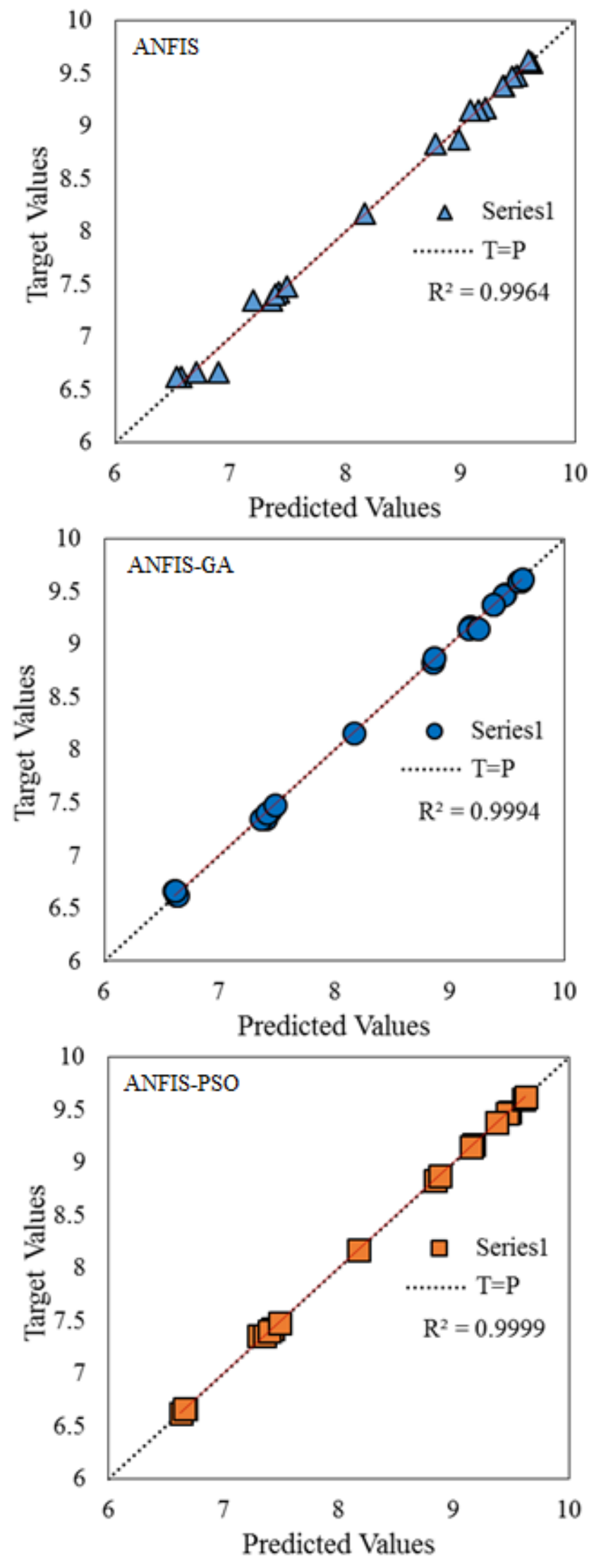

Fig. 5. Comparative analysis of the models for predicted values and $\mathrm{R}^{2}$

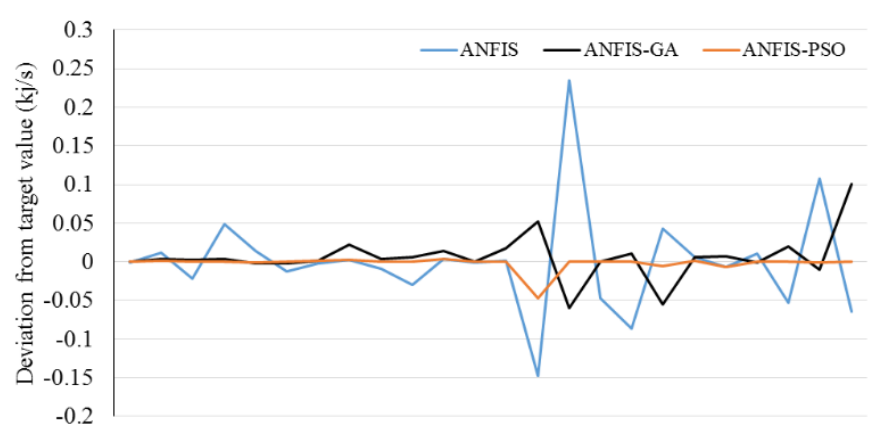

Fig. 6. Comparative deviation from the target value for the exergy destruction $(\mathrm{KJ} / \mathrm{s})$ for three models.

\section{CONCLUSION}

The hybridization of machine learning methods with soft computing techniques is an essential approach to improve the performance of the prediction models. Hybrid machine learning models, particularly, have gained popularity in the advancement of the high-performance control systems. Higher accuracy and better performance for prediction models of exergy destruction and energy consumption used in the control circuit of HVAC systems can be highly economical in the industrial scale to save energy. This research proposes two hybrid models of ANFISPSO and ANFIS-GA for the HVAC control system. The results are further compared with the single ANFIS model. The ANFISPSO model with the RMSE of 0.0065, MAE of 0.0028, and R2 equal to 0.9999 , with a minimum deviation of $0.0691(\mathrm{KJ} / \mathrm{s})$, outperforms the ANFIS-GA and single ANFIS models. For the future research, advancement of hybrid and ensemble machine learning models, e.g., [47-52], and comparative analysis with deep learning models, e.g., [53-56] are proposed to identify models with higher efficiency.

\section{ACKNOWLEDGMENT}

We acknowledge the financial support of this work by the Hungarian State and the European Union under the EFOP-3.6.116-2016-00010 project and the 2017-1.3.1-VKE-2017-00025 project.

\section{REFERENCES}

[1] Aid, A., Khan, M.A., Abbas, S., Ahmad, G., and Fatimat, A.: 'Modelling smart road traffic congestion control system using machine learning techniques', Neural Network World, 2019, 29, (2), pp. 99-110

[2] Alsrehin, N.O., Klaib, A.F., and Magableh, A.: 'Intelligent Transportation and Control Systems Using Data Mining and Machine Learning Techniques: A Comprehensive Study', IEEE Access, 2019, 7, pp. 4983049857

[3] Madanan, M., Hussain, N., Velayudhan, N.C., and Sayed, B.T.: 'Embedding machine learning in air traffic control systems to generate effective route plans for aircrafts in order to avoid collisions', J. Theor. Appl. Inf. Technol., 2019, 97, (2), pp. 605-616

[4] Ahn, J., and Cho, S.: 'Dead-band vs. machine-learning control systems: Analysis of control benefits and energy efficiency', J. Build. Eng., 2017, 12, pp. $17-25$

[5] Shah, V., and Putnik, G.D.: 'Machine learning based manufacturing control system for intelligent cyber-physical systems', FME Trans., 2019, 47, (4), pp. 802-809

[6] Wang, T., Kwok, T.H., Zhou, C., and Vader, S.: 'In-situ droplet inspection and closed-loop control system using machine learning for liquid metal jet printing', J Manuf Syst, 2018, 47, pp. 83-92 
[7] Aguilera, J.J., Kazanci, O.B., and Toftum, J.: 'Thermal adaptation in occupant-driven HVAC control', J. Build. Eng., 2019, 25

[8] Jung, W., Jazizadeh, F., and Diller, T.E.: 'Heat flux sensing for machinelearning-based personal thermal comfort modeling', Sensors, 2019, 19, (17)

[9] Pertzborn, A.: 'Using distributed agents to optimize thermal energy storage', J. Energy Storage, 2019, 23, pp. 89-97

[10] Aftab, M., Chen, C., Chau, C.K., and Rahwan, T.: 'Automatic HVAC control with real-time occupancy recognition and simulation-guided model predictive control in low-cost embedded system', Energy Build., 2017, 154, pp. 141-156

[11] Ghahramani, A., Karvigh, S.A., and Becerik-Gerber, B.: 'HVAC system energy optimization using an adaptive hybrid metaheuristic', Energy Build., 2017, 152, pp. 149-161

[12] Peng, Y., Rysanek, A., Nagy, Z., and Schlüter, A.: 'Using machine learning techniques for occupancy-prediction-based cooling control in office buildings', Appl. Energy, 2018, 211, pp. 1343-1358

[13] Xu, Y., Chen, S., Javed, M., Li, N., and Gan, Z.: 'A multi-occupants' comfort-driven and energy-efficient control strategy of VAV system based on learned thermal comfort profiles', Sc. Tech. Built Environ., 2018, 24, (10), pp. 1141-1149

[14] Lu, S., Wang, W., Lin, C., and Hameen, E.C.: 'Data-driven simulation of a thermal comfort-based temperature set-point control with ASHRAE RP884', Build. Environ., 2019, 156, pp. 137-146

[15] Ardabili, S.F., Najafi, B., Ghaebi, H., Shamshirband, S., and Mostafaeipour, A.: 'A novel enhanced exergy method in analyzing HVAC system using soft computing approaches: A case study on mushroom growing hall', J. Build. Eng., 2017, 13, pp. 309-318

[16] Afram, A., Fung, A.S., Janabi-Sharifi, F., and Raahemifar, K.: 'Development and performance comparison of low-order black-box models for a residential HVAC system', J. Build. Eng., 2018, 15, pp. 137155

[17] Afram, A., Janabi-Sharifi, F., Fung, A.S., and Raahemifar, K.: 'Artificial neural network (ANN) based model predictive control (MPC) and optimization of HVAC systems: A state of the art review and case study of a residential HVAC system', Energy Build., 2017, 141, pp. 96-113

[18] Alamin, Y.I., Álvarez, J.D., del Mar Castilla, M., and Ruano, A.: 'An Artificial Neural Network (ANN) model to predict the electric load profile for an HVAC system *', IFAC-PapersOnLine, 2018, 51, (10), pp. 26-31

[19] Baranski, M., Meyer, L., Fütterer, J., and Müller, D.: 'Comparative study of neighbor communication approaches for distributed model predictive control in building energy systems', Energy, 2019, 182, pp. 840-851

[20] Elnour, M., Meskin, N., and Al-Naemi, M.: 'Sensor data validation and fault diagnosis using Auto-Associative Neural Network for HVAC systems', J. Build. Eng., 2020, 27

[21] Ning, M., and Zaheeruddin, M.: 'Neural network model-based adaptive control of a VAV-HVAC\&R system', Intl. J. Air-Conditioning Refrig., 2019, 27, (1)

[22] Peng, Y., Nagy, Z., and Schlüter, A.: 'Temperature-preference learning with neural networks for occupant-centric building indoor climate controls', Build. Environ., 2019, 154, pp. 296-308

[23] Son, J., and Kim, H.: 'Sensorless air flow control in an HVAC system through deep learning', Appl. Sci., 2019, 9, (16)

[24] Homod, R.Z.: 'Analysis and optimization of HVAC control systems based on energy and performance considerations for smart buildings', Renew. Energy, 2018, 126, pp. 49-64

[25] Javed, A., Larijani, H., Ahmadinia, A., and Gibson, D.: 'Smart Random Neural Network Controller for HVAC Using Cloud Computing Technology', IEEE Trans. Ind. Inf., 2017, 13, (1), pp. 351-360

[26] Li, D., Menassa, C.C., and Kamat, V.R.: 'Personalized human comfort in indoor building environments under diverse conditioning modes', Build. Environ., 2017, 126, pp. 304-317

[27] Orosa, J.A., Vergara, D., Costa, Á.M., and Bouzón, R.: 'A novel method based on neural networks for designing internal coverings in buildings: Energy saving and thermal comfort', Appl. Sci., 2019, 9, (10)

[28] Ou, T.C., Lu, K.H., and Huang, C.J.: 'Improvement of transient stability in a hybrid power multi-system using a designed NIDC (Novel Intelligent Damping Controller)', Energies, 2017, 10, (4)

[29] Reynolds, J., Rezgui, Y., Kwan, A., and Piriou, S.: 'A zone-level, building energy optimisation combining an artificial neural network, a genetic algorithm, and model predictive control', Energy, 2018, 151, pp. 729-739
[30] Tian, Z., Si, B., Wu, Y., Zhou, X., and Shi, X.: 'Multi-objective optimization model predictive dispatch precooling and ceiling fans in office buildings under different summer weather conditions', Build. Simul., 2019, 12, (6), pp. 999-1012

[31] Wang, Y., Velswamy, K., and Huang, B.: 'A Novel Approach to Feedback Control with Deep Reinforcement Learning*', IFACPapersOnLine, 2018, 51, (18), pp. 31-36

[32] Colledanchise, M., and Ogren, P.: 'How Behavior Trees Modularize Hybrid Control Systems and Generalize Sequential Behavior Compositions, the Subsumption Architecture, and Decision Trees', IEEE Trans. Rob., 2017, 33, (2), pp. 372-389

[33] Phu Do, X., Hung Nguyen, Q., and Choi, S.B.: 'New hybrid optimal controller applied to a vibration control system subjected to severe disturbances', Mech Syst Signal Process, 2019, 124, pp. 408-423

[34] Rosienkiewicz, M., Kowalski, A., Helman, J., and Zbieć, M.: 'Development of lean hybrid furniture production control system based on glenday sieve, artificial neural networks and simulation modeling', Drvna Ind., 2018, 69, (2), pp. 163-173

[35] Schmalfuss, L., Hahne, J., Farina, D., Hewitt, M., Kogut, A., Doneit, W., Reischl, M., Rupp, R., and Liebetanz, D.: 'A hybrid auricular control system: Direct, simultaneous, and proportional myoelectric control of two degrees of freedom in prosthetic hands', J. Neural Eng., 2018, 15, (5)

[36] Abbasi, E., and Hadji Hosseinlou, M.: 'The Importance of Exercise and General Mental Health on Prediction of Property-Damage-Only Accidents among Taxi Drivers in Tehran: A Study Using ANFIS-PSO and Regression Models', J Adv Transp, 2019, 2019

[37] Ebtehaj, I., Bonakdari, H., and Es-haghi, M.S.: 'Design of a Hybrid ANFIS-PSO Model to Estimate Sediment Transport in Open Channels', Iran. J. Sci. Tech. Trans. Civ. Eng., 2019, 43, (4), pp. 851-857

[38] Salisu, S., Mustafa, M.W., Mustapha, M., and Mohammed, O.O.: 'Solar radiation forecasting in Nigeria based on hybrid PSO-ANFIS and WTANFIS approach', Int. J. Electr. Comput. Eng., 2019, 9, (5), pp. 39163926

[39] Zhou, J., Li, C., Arslan, C.A., Hasanipanah, M., and Bakhshandeh Amnieh, H.: 'Performance evaluation of hybrid FFA-ANFIS and GAANFIS models to predict particle size distribution of a muck-pile after blasting', Eng Comput, 2019

[40] Dasari, M., Srinivasula Reddy, A., and Vijaya Kumar, M.: 'GA-ANFIS PID compensated model reference adaptive control for BLDC motor', Int. J. Power Electron. Drive Syst., 2019, 10, (1), pp. 265-276

[41] Dasari, M., Reddy, A.S., and Kumar, M.V.: 'GA-ANFIS PID compensated MRAC for BLDC motor', ARPN J. Eng. Appl. Sci., 2018, 13, (23), pp. 9123-9131

[42] Ravi, S., Sudha, M., and Balakrishnan, P.A.: 'Design of intelligent selftuning GA ANFIS temperature controller for plastic extrusion system', Model. Simul. Eng., 2011, 2011

[43] Esfandiarian, A., and Sedaghat, M.: 'Development of a novel ANFIS-GA method for investigation of effect of inhibitors on asphaltene precipitation', Petrol Sci Technol, 2019, 37, (14), pp. 1626-1633

[44] Atuahene, S., Bao, Y., Yevenyo Ziggah, Y., Semwaah Gyan, P., and Li, F.: 'Short-term electric power forecasting using dual-stage hierarchical wavelet- Particle swarm optimization- Adaptive neuro-fuzzy inference system pso-ANFIS approach based on climate change', Energies, 2018, $11,(10)$

[45] Catalão, J.P.S., Pousinho, H.M.I., and Mendes, V.M.F.: 'Hybrid waveletPSO-ANFIS approach for short-term electricity prices forecasting', IEEE Trans Power Syst, 2011, 26, (1), pp. 137-144

[46] Basser, H., Karami, H., Shamshirband, S., Akib, S., Amirmojahedi, M., Ahmad, R., Jahangirzadeh, A., and Javidnia, H.: 'Hybrid ANFIS-PSO approach for predicting optimum parameters of a protective spur dike', Applied Soft Computing, 2015, 30, pp. 642-649

[47] Ardabili, S., Mosavi, A., and Várkonyi-Kóczy, A.R.: Advances in Machine Learning Modeling Reviewing Hybrid and Ensemble Methods, 2020, Lecture Notes in Networks and Systems 101, pp. 215-227.

[48] Ardabili, S., Mosavi, A., and Várkonyi-Kóczy, A.R., Systematic Review of Deep Learning and Machine Learning Models in Biofuels Research, 2020, Lecture Notes in Networks and Systems 101, pp. 19-32

[49] Gundoshmian, T.M., Ardabili, S., Mosavi, A., and Várkonyi-Kóczy, A.R. Prediction of Combine Harvester Performance Using Hybrid Machine Learning Modeling and Response Surface Methodology, 2020, Lecture Notes in Networks and Systems 101, pp. 345-360 
[50] Joloudari, J.H., Joloudari, E.H., Saadatfar, H., Ghasemigol, M., Razavi, S.M., Mosavi, A., Nabipour, N., Shamshirband, S., and Nadai, L. Coronary artery disease diagnosis; ranking the significant features using a random trees model, Int. J. Environ. Res. Public Health, 2020, 17, (3)5.

[51] Nosratabadi, S., Mosavi, A., Keivani, R., Ardabili, S., and Aram, F. State of the Art Survey of Deep Learning and Machine Learning Models for Smart Cities and Urban Sustainability, 2020, Lecture Notes in Networks and Systems 101, pp. 228-238

[52] Ardabili, S., Mosavi, A., Dehghani, M., and Várkonyi-Kóczy, A.R. Deep Learning and Machine Learning in Hydrological Processes Climate Change and Earth Systems a Systematic Review, 2020, Lecture Notes in Networks and Systems 101, pp. 52-62.
[53] Ardabili, S., Mosavi, A., Mahmoudi, A., Gundoshmian, T.M., Nosratabadi, S., and Várkonyi-Kóczy, A.R. Modelling Temperature Variation of Mushroom Growing Hall Using Artificial Neural Networks, 2020, Lecture Notes in Networks and Systems 101, pp. 33-45.

[54] Mosavi, A., Ozturk, P., \& Chau, K. W. Flood prediction using machine learning models: Literature review. Water, 2018, 10 (11), 1536.

[55] Ardabili, S., Mosavi, A., and Várkonyi-Kóczy, A.R. Building Energy Information: Demand and Consumption Prediction with Machine Learning Models for Sustainable and Smart, 2020, Lecture Notes in Networks and Systems 101, pp. 191-201.

[56] Mosavi, A., Ardabili, S., and Várkonyi-Kóczy, A.R. List of Deep Learning Models, 2020, Lecture Notes in Networks and Systems 101, pp. 202-214. 